NOTA

\title{
ESPAÇAMENTOS PARA PRODUÇÃO DE SEMENTES DE GUANDU EM SEMEADURA TARDIA ${ }^{(1)}$
}

\author{
GERSON SILVA GIOMO ${ }^{(2)}$; LUIZ FERNANDES RAZERA ${ }^{(2)}$; \\ JOÃO NAKAGAWA ${ }^{(3,4)}$

\section{RESUMO}

Avaliaram-se os efeitos dos espaçamentos entre linhas e entre plantas na linha em algumas características das plantas e na produção de sementes de guandu [Cajanus cajan (L.) Millsp.], em semeadura tardia (março/1996), em experimento instalado no Núcleo Experimental do Instituto Agronômico, em Campinas (SP). Utilizaram-se dois espaçamentos entre linhas (75 e $100 \mathrm{~cm}$ ) e dois entre plantas na linha $(7$ e $10 \mathrm{~cm})$, perfazendo quatro tratamentos no delineamento inteiramente casualizado, em esquema fatorial $2 \times 2$ com três repetições. Avaliaram-se, também, a população final de plantas, altura da planta e de inserção da primeira vagem, diâmetro do caule, número de ramos por planta, produção de vagens e sementes por planta, porcentagem de vagens chochas, contribuição dos ramos na produção da planta e produtividade de sementes. Verificou-se que o diâmetro do caule, o número de ramos primários por planta, a produção de vagens nos ramos e a contribuição destes na produção foram independentemente afetados nas diferentes densidades populacionais, correspondendo aos valores inferiores os espaçamentos menores. A produtividade de sementes, em média $821 \mathrm{~kg} \cdot \mathrm{ha}^{-1}$, não foi significativamente afetada nos espaçamentos estudados, do que se conclui que qualquer um deles pode ser utilizado para a produção de sementes de guandu, em condições de semeadura tardia. As plantas apresentaram porte baixo, caule fino e maturação uniforme de vagens, requisitos considerados importantes para a realização de colheita mecanizada de sementes.

Palavras-chave: guandu, Cajanus cajan (L.) Millsp., sementes, produção, espaçamentos.

\section{ABSTRACT \\ SPACINGS FOR PIGEONPEA SEED PRODUCTION AT LATE SOWING}

Pigeonpea seed production was evaluated in a field plot experiment, sowed at late planting date (march/1996) in the Experiment Station of Instituto Agronômico, at Campinas, State of São Paulo, Brazil. The treatments consisted of two row spacings $(75$ and $100 \mathrm{~cm})$ and two plant spacings $(7$ and $10 \mathrm{~cm}$ ), arranged in a $2 \times 2$ factorial with three replications, in a completely randomized design. The parameters evaluated were plant population, plant and pod insertion height, stem diameter, number of branches, pods and seed production per plant, percentage of empty pods, branches contribution on yield, and seed yield. The spacings showed statistically significant effects on stem diameter, number of pods and branches per plant, and contribution of branches on seed production. The plants had lower height, smaller stem diameter and uniform pod maturation, and all these characters are important points to be considered for mechanical harvest purposes. The average seed yield was $821 \mathrm{~kg} \cdot \mathrm{ha}^{-1}$ and all studied spacings were adequate for the pigeonpea seed production at late sowing.

Key words: pigeonpea, Cajanus cajan (L.) Millsp., seeds, yield, spacings.

(1) Recebido para publicação em 19 de julho de 2000 e aceito em 30 de março de 2001.

( ${ }^{2}$ ) Centro de Produção de Material Propagativo, Instituto Agronômico (IAC), Caixa Postal 28, 13001-970 Campinas (SP). E-mail: gsgiomo@cec.iac.br

$\left({ }^{3}\right)$ Departamento de Produção Vegetal, Faculdade de Ciências Agronômicas (UNESP), Caixa Postal 237, $18603-970$ Botucatu (SP). E-mail: secdamv@fca.unesp.br

( ${ }^{4}$ Com bolsa de produtividade em pesquisa do CNPq. 


\section{Introdução}

O guandu [Cajanus cajan (L.) Millsp.] tem-se destacado no Brasil, entre outras leguminosas forrageiras, em função de sua notável tolerância à seca e adaptação aos solos pouco férteis, apresentando grande potencial de produção de fitomassa, mesmo em períodos de estiagem (WUTKE, 1987).

Em estudos de população de plantas e época de semeadura de guandu, SINGH et al. (1971) obtiveram aumento significativo na produtividade de sementes com o incremento na densidade populacional e, embora não tenha sido observado o efeito da época de semeadura na produtividade, verificou-se a seguinte correlação: produtividade tendencialmente menor na medida do atraso da semeadura.

DAHIYA et al. (1974) verificaram, em várias cultivares de guandu, que a altura da planta e a produção de vagens e sementes por planta foram menores em semeadura tardia. Porém, como a produção de matéria seca por planta também foi menor, o índice de colheita na semeadura tardia foi maior que na semeadura em época normal.

REDDY et al. (1991) observaram desenvolvimento vegetativo e produção de sementes por planta menores em semeaduras tardias de guandu, o que enfatizou a necessidade do aumento da população de plantas para a obtenção de maior produtividade de sementes nessas condições.

Segundo MirANDA et al. (1989), a 'IAC-Fava Larga' é uma planta arbustiva que apresenta $2,7 \mathrm{~m}$ de altura e ciclo até de 280 dias, quando semeada em época normal (outubro-janeiro). No entanto, se a semeadura for realizada em fevereiro, pode-se reduzir a altura para 1,8-2,0 m e o ciclo para 225-230 dias, facilitando a colheita de sementes.

Recomendou-se, por muito tempo, no Estado de São Paulo, o espaçamento de $100 \mathrm{~cm}$ entre linhas, densidade de 10 plantas por metro e semeadura em fevereiro para a produção de sementes de guandu (BRAGa e Bulisani, 1990). Mais recentemente, WutKe et al. (1998) preconizaram o espaçamento de 50 a $100 \mathrm{~cm}$ entre linhas, dependendo da época de semeadura, confirmando as observações feitas por SINGH et al. (1971), DAHIYA et al. (1974) e REDDY et al. (1991). Mesmo não havendo consenso quanto às épocas de semeadura e espaçamentos para produção de sementes de guandu, observa-se na maioria dos trabalhos a necessidade de ajuste da população de plantas em função da época de semeadura, evitando, assim, perda na produtividade de sementes.

Tendo em vista a escassez de informações sobre a produção de sementes de guandu em semeadura tardia, objetivou-se, neste trabalho, avaliar os efeitos de diferentes arranjos populacionais em algumas características das plantas e definir o mais adequado para esse fim, utilizando-se, para tanto, a cultivar IACFava Larga.

\section{Material e Métodos}

O experimento foi desenvolvido em condições de campo, no ano agrícola de 1996/1997, no Núcleo Experimental do Instituto Agronômico, Campinas (SP), em Latossolo Vermelho. Utilizou-se o delineamento estatístico inteiramente casualizado, em esquema fatorial $2 \times 2$ com três repetições; os tratamentos consistiram em dois espaçamentos entre linhas $(75$ e $100 \mathrm{~cm})$ e dois entre plantas na linha $(7 \mathrm{e}$ $10 \mathrm{~cm}$ ), com parcelas de $6 \times 4 \mathrm{~m}$, espaçadas de $1,0 \mathrm{~m}$ entre si, com 9 e 7 linhas, respectivamente, para os espaçamentos de 75 e $100 \mathrm{~cm}$ entre linhas.

Para a adubação, seguiram-se as recomendações de BRAGA e BuLISANI (1990), aplicando-se 205 kg.ha ${ }^{-1}$ da fórmula 4-20-20. A semeadura foi realizada manualmente em 14/3/1996, distribuindo-se 40 sementes da cultivar IAC-Fava Larga de guandu por metro de sulco. Duas semanas após a emergência, fez-se o desbaste, deixando-se o número de plantas previsto em cada tratamento. O experimento foi mantido livre de plantas daninhas até 60 dias após a semeadura, por meio de duas capinas manuais.

Avaliaram-se emergência de plântulas, florescimento, frutificação, maturação das vagens e população final de plantas na colheita. Maturadas as vagens, cortaram-se dez plantas de cada parcela, avaliando-as em algumas de suas características, tais como altura da planta e de inserção da primeira vagem, diâmetro do caule, número de ramos por planta e a contribuição destes na produção de sementes.

Anotaram-se, separadamente, dados da produção de vagens e de sementes para a haste principal e para os ramos e, da soma destes, obtiveram-se os dados médios por planta. A porcentagem de vagens chochas também foi avaliada em separado para haste e ramos, cujas médias constituíram a porcentagem de vagens chochas na planta. Consideraram-se como chochas as vagens sem sementes.

A colheita de sementes também foi realizada manualmente, em uma única vez, em 4/10/1996, quando a maioria das vagens se encontrava madura. As duas linhas externas e 0,5 $\mathrm{m}$ das extremidades de cada parcela foram desprezadas como bordadura, resultando em área útil diferente para cada espaçamento entre linhas. As vagens foram secas ao sol e, em seguida, debulhadas mecanicamente. 
Estimou-se a produtividade de sementes com base na produção da área útil das parcelas após o devido descarte de sementes quebradas, defeituosas, pequenas e/ou mal formadas, retidas em peneiras com perfurações oblongas menores que 11 x 3/4".

Analisaram-se os dados estatisticamente, segundo as recomendações de Gomes (1966). Valores expressos em porcentagem e em número foram transformados, respectivamente, em arco seno da raiz quadrada da porcentagem e raiz quadrada do número. Nos resultados, porém, são apresentados os dados originais.

\section{Resultados e Discussão}

O florescimento, a frutificação e a maturação de vagens ocorreram simultaneamente em todos os tratamentos, indicando a não-influência dos diferentes espaçamentos. A emergência de plântulas, os $50 \%$ do florescimento e os $50 \%$ da formação de vagens ocorreram, respectivamente, aos 6, 98 e 116 dias após a semeadura. O ciclo da planta, da semeadura à colheita, foi de 204 dias, menor, portanto, que os citados por Miranda et al. (1989), de 280 e 225 dias para semeaduras em outubro e fevereiro respectivamente, revelando que, mediante a semeadura tardia (março), favoreceu-se o encurtamento da fase vegetativa e a diminuição do ciclo da planta. As plantas apresentaram apenas ramificação primária, provavelmente em conseqüência do menor desenvolvimento vegetativo ocasionado pela semeadura tardia e pelos espaçamentos adensados.

Pelos dados do quadro 1 observa-se que, no momento da colheita, as populações de plantas foram estatisticamente diferentes somente nos espaçamentos entre plantas na linha. Comparando-se as populações obtidas na colheita com as populações planejadas, é possível verificar que aquelas foram sempre inferiores às planejadas, em função da mortalidade de plantas ocorrida após o desbaste, por causa dos fungos de solo (Rhizoctonia spp. e Fusarium spp.) e das formigas cortadeiras (saúvas). Em algumas parcelas, a população de plantas, no momento do desbaste, já era inferior à desejada. Assim, a alta densidade de semeadura não garantiu a população ideal de plantas na colheita. Em face dessas constatações, confirma-se a dificuldade de obtenção de altas densidades populacionais de guandu em estudos de espaçamentos, em condições de campo, devido às adversidades encontradas.

Apesar de não ter ocorrido diferença significativa entre as populações dos espaçamentos entre linhas, observa-se uma variação de aproximadamente 20.000 plantas.ha ${ }^{-1}$ entre o maior e o menor espaçamento, o que pode ter causado efeitos biológicos distintos,
Quadro 1. Populações de plantas de guandu, planejadas e obtidas na colheita, em função da variação dos espaçamentos

\begin{tabular}{lrcc}
\hline Espaçamentos & $\mathrm{c}$ & $\begin{array}{c}\text { População } \\
\text { planejada }\end{array}$ & $\begin{array}{c}\text { População } \\
\text { na colheita }\end{array}$ \\
\hline Entre linhas & 75 & 167.676 & $125.080 \mathrm{a}$ \\
& 100 & 125.757 & $105.445 \mathrm{a}$ \\
Entre plantas & 7 & 176.767 & $135.572 \mathrm{~A}$ \\
na linha & 10 & 116.666 & $94.952 \mathrm{~B}$ \\
Média & - & 146.716 & 115.262 \\
C.V. $(\%)$ & - & & 18,8 \\
\hline
\end{tabular}

Médias seguidas pela mesma letra na coluna, minúsculas para espaçamentos entre linhas e maiúsculas para espaçamentos entre plantas na linha, não diferem significativamente entre si, pelo teste $\mathrm{T}$ (LSD), a $5 \%$ de probabilidade.

tanto nas características das plantas quanto na produção de sementes. A população média obtida na colheita (115.262 plantas.ha $^{-1}$ ) foi um pouco superior à população de 100.000 plantas.ha $^{-1}$ recomendada por BRAGA e BULISANI (1990), porém bastante inferior à população de 200.000 plantas.ha $^{-1}$, recomendada por WUTKE et al. (1998) para a produção de sementes de guandu em semeaduras tardias no Estado de São Paulo.

Verifica-se que, tanto a altura da planta quanto a de inserção da primeira vagem não foram significativamente afetadas pelos espaçamentos (Quadro 2). Em todos eles, as plantas apresentaram porte baixo $(0,91$ a $0,94 \mathrm{~m})$, quando comparado com os resultados descritos por DE MARCHI et al. (1984), que verificaram altura de planta entre 1,63 e 1,80 m em semeadura efetuada em janeiro. As alturas das plantas também foram bastante inferiores à de 1,8-2,0 m, citada por MiRANDA et al. (1989) para semeadura de 'IAC-Fava Larga', em fevereiro. Isso mostra o efeito isolado da semeadura tardia (março) na redução da altura da planta, visto que não houve influência dos espaçamentos.

A altura média de inserção da primeira vagem $(0,65 \mathrm{~m})$ pode ser considerada alta, oferecendo condições adequadas para o corte das plantas a $0,50 \mathrm{~m}$ de altura, sem a possível perda de vagens na colheita mecanizada. O diâmetro do caule foi afetado apenas pelos espaçamentos entre plantas na linha. O menor valor foi observado no espaçamento de $7 \mathrm{~cm}$ entre plantas na linha, diferindo significativamente do espaçamento de $10 \mathrm{~cm}$. Os baixos valores de diâmetro do caule, observados em todos os espaçamentos $(7,9$ a $8,8 \mathrm{~mm})$, constituem fator de grande importância 
Quadro 2. Altura da planta, altura de inserção da primeira vagem, diâmetro do caule e número de ramos por planta de guandu, em função da variação dos espaçamentos

\begin{tabular}{|c|c|c|c|c|c|}
\hline \multirow{2}{*}{ Espaçamentos } & & \multicolumn{2}{|c|}{ Altura } & \multirow{2}{*}{$\begin{array}{l}\text { Diâmetro } \\
\text { do caule }\end{array}$} & \multirow{2}{*}{$\begin{array}{c}\text { Ramos } \\
\text { por planta }\end{array}$} \\
\hline & & Planta & Inserção da vagem & & \\
\hline & $\mathrm{cm}$ & 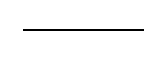 & $\mathrm{m}$ & $\mathrm{mm}$ & n. ${ }^{o}$ \\
\hline Entre linhas & $\begin{array}{r}75 \\
100\end{array}$ & $\begin{array}{l}0,93 \mathrm{a} \\
0,92 \mathrm{a}\end{array}$ & $\begin{array}{l}0,64 \mathrm{a} \\
0,65 \mathrm{a}\end{array}$ & $\begin{array}{l}8,3 \mathrm{a} \\
8,5 \mathrm{a}\end{array}$ & $\begin{array}{l}5 \mathrm{~b} \\
6 \mathrm{a}\end{array}$ \\
\hline Entre plantas na linha & $\begin{array}{r}7 \\
10\end{array}$ & $\begin{array}{l}0,91 \mathrm{~A} \\
0,94 \mathrm{~A}\end{array}$ & $\begin{array}{l}0,66 \mathrm{~A} \\
0,63 \mathrm{~A}\end{array}$ & $\begin{array}{l}7,9 \mathrm{~B} \\
8,8 \mathrm{~A}\end{array}$ & $\begin{array}{l}5 \mathrm{~A} \\
5 \mathrm{~A}\end{array}$ \\
\hline Média & - & 0,93 & 0,65 & 8,4 & 5 \\
\hline C.V. $(\%)$ & - & 7,2 & 8,3 & 5,6 & 15,2 \\
\hline
\end{tabular}

Médias seguidas pela mesma letra na coluna, minúscula para espaçamentos entre linhas e maiúscula para espaçamentos entre plantas na linha, não diferem significativamente entre si, pelo teste T (LSD), a 5\% de probabilidade.

para a colheita mecanizada de sementes, pois pode-se considerá-los não limitantes ao corte das plantas.

As plantas apresentaram apenas ramificação primária, com média de cinco ramos por planta, confirmando menor desenvolvimento vegetativo devido à semeadura tardia, conforme observado por SINGH et al. (1971), DAHIYA et al. (1974) e REDDY et al. (1991). O número de ramos por planta foi significativamente afetado nos espaçamentos entre linhas, sendo inferior no menor espaçamento $(75 \mathrm{~cm})$, à semelhança dos dados obtidos por DE MARCHI et al. (1982), que também verificaram menor formação de ramos na planta de guandu, cultivar Kaki, como conseqüência da maior competição entre plantas no espaçamento de $50 \mathrm{~cm}$ entre linhas.

De acordo com o quadro 3, a produção de vagens dos ramos nos maiores espaçamentos $(100 \mathrm{~cm}$ entre linhas e $10 \mathrm{~cm}$ entre plantas na linha) foi significativamente maior do que nos menores espaçamentos (75 e $7 \mathrm{~cm}$ ). A produção de vagens por planta foi semelhante nos dois espaçamentos, observou-se, no en- tanto, que nos maiores, a produção por planta resultou de maior contribuição dos ramos primários, enquanto nos menores, a contribuição dos ramos foi equivalente à da haste principal. As plantas produziram, em média, 28 vagens, correspondendo a 50\% do valor obtido por DE MARCHI et al. (1984), para semeadura em época normal (janeiro) e com populações inferiores a 50.000 plantas por hectare.

A porcentagem de vagens chochas não foi significativamente afetada pelos espaçamentos em nenhuma das partes amostradas da planta. Observase, porém, maior valor desse parâmetro nos ramos primários, provavelmente devido à formação inicial de vagens na haste principal, estabelecendo-se competição com os ramos por nutrientes para a formação de sementes e enchimento de vagens. Em $26 \%$ do total de vagens produzidas pela planta, não houve produção de sementes, ou seja, apenas $74 \%$ das vagens estavam granadas.

Os resultados apresentados no quadro 4 mostram que, embora a produção de sementes por planta não

Quadro 3. Produção de vagens e porcentagem de vagens chochas, na haste, nos ramos e na planta de guandu, em função da variação dos espaçamentos

\begin{tabular}{|c|c|c|c|c|c|c|c|}
\hline \multirow{2}{*}{ Espaçamentos } & & \multicolumn{3}{|c|}{ Produção de vagens } & \multicolumn{3}{|c|}{ Vagens chochas } \\
\hline & & Haste & Ramos & Planta & Haste & Ramos & Planta \\
\hline & $\mathrm{cm}$ & $\longrightarrow$ & $-\mathrm{n}^{\mathrm{o}}-$ & - & 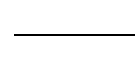 & $-\%$ & - \\
\hline Entre linhas & $\begin{array}{r}75 \\
100\end{array}$ & $\begin{array}{l}13 \mathrm{a} \\
13 \mathrm{a}\end{array}$ & $\begin{array}{l}12 \mathrm{~b} \\
17 \mathrm{a}\end{array}$ & $\begin{array}{l}25 a \\
30 a\end{array}$ & $\begin{array}{l}21,9 \mathrm{a} \\
24,6 \mathrm{a}\end{array}$ & $\begin{array}{l}28,1 \mathrm{a} \\
30,7 \mathrm{a}\end{array}$ & $\begin{array}{l}25,0 \mathrm{a} \\
27,7 \mathrm{a}\end{array}$ \\
\hline Entre plantas na linha & $\begin{array}{r}7 \\
10\end{array}$ & $\begin{array}{l}13 \mathrm{~A} \\
13 \mathrm{~A}\end{array}$ & $\begin{array}{l}12 \mathrm{~B} \\
17 \mathrm{~A}\end{array}$ & $\begin{array}{l}25 \mathrm{~A} \\
30 \mathrm{~A}\end{array}$ & $\begin{array}{l}23,5 \mathrm{~A} \\
23,0 \mathrm{~A}\end{array}$ & $\begin{array}{l}28,8 \mathrm{~A} \\
30,0 \mathrm{~A}\end{array}$ & $\begin{array}{l}26,2 \mathrm{~A} \\
26,5 \mathrm{~A}\end{array}$ \\
\hline Média & - & 13 & 15 & 28 & 23,3 & 29,4 & 26,4 \\
\hline C.V. $(\%)$ & - & 21,0 & 20,6 & 20,0 & 16,1 & 11,5 & 10,7 \\
\hline
\end{tabular}

Médias seguidas pela mesma letra na coluna, minúscula para espaçamentos entre linhas e maiúscula para espaçamentos entre plantas na linha, não diferem significativamente entre si, pelo teste T (LSD), a 5\% de probabilidade. 
Quadro 4. Produção de sementes na haste principal, nos ramos e na planta, contribuição dos ramos na produção e produtividade de sementes, em função da variação dos espaçamentos

\begin{tabular}{|c|c|c|c|c|c|c|}
\hline \multirow{2}{*}{ Espaçamentos } & & \multicolumn{3}{|c|}{ Produção de sementes } & \multirow{2}{*}{$\begin{array}{l}\text { Contribuição } \\
\text { dos ramos }\end{array}$} & \multirow{2}{*}{$\begin{array}{c}\text { Produtividade } \\
\text { de sementes }\end{array}$} \\
\hline & & Haste & Ramos & Planta & & \\
\hline & $\mathrm{cm}$ & 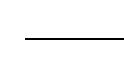 & - g - & - & $\%$ & kg.ha ${ }^{-1}$ \\
\hline Entre linhas & $\begin{array}{r}75 \\
100\end{array}$ & $\begin{array}{l}4,87 \mathrm{a} \\
5,33 \mathrm{a}\end{array}$ & $\begin{array}{l}4,18 \mathrm{a} \\
5,70 \mathrm{a}\end{array}$ & $\begin{array}{r}9,05 \mathrm{a} \\
11,03 \mathrm{a}\end{array}$ & $\begin{array}{l}46,1 \mathrm{a} \\
50,7 \mathrm{a}\end{array}$ & $\begin{array}{l}818,8 \mathrm{a} \\
822,9 \mathrm{a}\end{array}$ \\
\hline Entre plantas na linha & $\begin{array}{r}7 \\
10\end{array}$ & $\begin{array}{l}5,34 \mathrm{~A} \\
4,87 \mathrm{~A}\end{array}$ & $\begin{array}{l}4,16 \mathrm{~A} \\
5,72 \mathrm{~A}\end{array}$ & $\begin{array}{r}9,50 \mathrm{~A} \\
10,59 \mathrm{~A}\end{array}$ & $\begin{array}{l}43,0 \mathrm{~B} \\
53,7 \mathrm{~A}\end{array}$ & $\begin{array}{l}862,7 \mathrm{~A} \\
778,9 \mathrm{~A}\end{array}$ \\
\hline Média & & 5,01 & 4,94 & 10,04 & 48,4 & 820,8 \\
\hline C.V. $(\%)$ & & 25,4 & 28,7 & 24,9 & 12,8 & 19,4 \\
\hline
\end{tabular}

Médias seguidas pela mesma letra na coluna, minúscula para espaçamentos entre linhas e maiúscula para espaçamentos entre plantas na linha, não diferem significativamente entre si, pelo teste T (LSD), a 5\% de probabilidade.

tenha sido significativamente afetada pela diferença de espaçamento, a maior produção tende a ocorrer nos maiores espaçamentos entre linhas e entre plantas na linha. Confirmam-se, pois, dados relatados por DE MARCHI et al. (1984), segundo os quais a menor produção por planta nos menores espaçamentos foi compensada pelo maior número de plantas, resultando em produtividade final semelhante à dos maiores.

A contribuição dos ramos primários na produção de sementes por planta foi significativamente incrementada à medida que se aumentou o espaçamento entre plantas na linha. $\mathrm{O}$ valor inferior, observado no menor espaçamento entre plantas $(7 \mathrm{~cm})$, pode ter ocorrido em função da menor produção de vagens nesses ramos que, conseqüentemente, proporcionou menor contribuição à produção de sementes por planta. A contribuição média dos ramos na produção por planta foi de $48 \%$, revelando-se importante para a produção de sementes por planta. Observa-se que, nos menores espaçamentos, tanto entre linhas quanto entre plantas na linha, a produção de sementes por planta foi condicionada à produção da haste principal, enquanto, nos maiores espaçamentos, a dependência foi dos ramos.

Embora a produtividade de sementes não tenha sido afetada de forma significativa pelos espaçamentos, foi numericamente superior no menor espaçamento entre plantas na linha, certamente pelo fato de a população de plantas ser significativamente superior no momento da colheita. Isso indica que a produção de sementes tende a aumentar com o aumento da população de plantas, confirmando os resultados de SINGH et al. (1971), DAHIYA et al. (1974) e REDDY et al. (1991).

Nos espaçamentos maiores, apesar de a população de plantas ter sido numericamente inferior e a produção de sementes por planta, superior, a produtivi- dade de sementes foi semelhante à dos espaçamentos menores. Em vista disso, infere-se que a produção de sementes nos espaçamentos maiores sofreu maior influência da produção de sementes por planta, enquanto nos menores, da população de plantas. Houve, assim, uma compensação na produção de sementes, resultando em produtividade semelhante em todos os espaçamentos, com densidades populacionais entre 94.952 e 135.572 plantas.ha $^{-1}$.

Considerando-se que a semeadura foi bastante tardia (março), com pouca e má distribuição de chuvas durante o experimento, a produtividade média de $821 \mathrm{~kg}$ de sementes.ha ${ }^{-1}$ foi satisfatória. A produtividade obtida no espaçamento de $100 \mathrm{~cm}$ entre linhas foi o dobro daquela obtida por LOVADINI e MASCARENHAS (1974), na mesma época de semeadura, com a cultivar Kaki. Contudo, ficou bem abaixo dos $1.683 \mathrm{~kg} \mathrm{ha}^{-1}$ obtidos por MirANDA et al. (1989) com a 'IAC-Fava Larga', semeada em fevereiro.

\section{Conclusão}

Os espaçamentos, por adequarem-se, indistintamente, à colheita mecanizada, mostraram-se aptos para a produção de sementes de guandu, cultivar IAC-Fava Larga, em semeadura tardia.

\section{Referências Bibliográficas}

BRAGA, N.R.; BULISANI, E.A. Feijão guandu - Cajanus Cajan (L.) Millsp. In: JORGE, J.A.; LOURENÇÃO, A.L.; ARANHA, C. (Eds.). Instruções agrícolas para o Estado de São Paulo. 5.ed. Campinas: Instituto Agronômico, 1990. p.100. (Boletim Técnico, 200)

DAHIYA, B.S.; BRAR, J.S.; KAUL, J.N. Changes in growth habit of pigeon-peas [(Cajanus cajan (L.) Millsp.)] due to late sowing. Journal of Agricultural Sciences, Cambridge, v.83, p.379-380, 1974. 
DE MARCHI, M.J.; NAKAGAWA, J.; MACHADO, J.R. Estudo de espaçamentos na cultura do guandu. II. Efeitos na produção de massa verde, seca e de sementes. Científica, São Paulo, v.10, n.2, p.277-283, 1982.

DE MARCHI, M.J.; NAKAGAWA, J.; MACHADO, J.R. Estudo de espaçamentos na cultura do guandu. IV. Efeitos na produção de sementes e nos componentes da produção. Revista de Agricultura, Piracicaba, v.59, p.83-97, 1984.

GOMES, F.P. Curso de estatística experimental. Piracicaba: Escola Superior de Agricultura "Luiz de Queiroz", 1966. 404p.

LOVADINI, L.A.C.; MASCARENHAS, H.A.A. Estudos para definição da melhor época de plantio do guandu. Bragantia, Campinas, v.33, n.15, p.V-VIII, 1974.

MIRANDA, M.A.C. de; WUTKE, E.B.; MARTINS, A.L.M. Cultivar de guandu IAC-Fava Larga. Campinas: Instituto Agronômico, 1989. (Fôlder)

REDDY, M.G.; GHOSH, B.C.; SUDHAKAR, N. Effect of time of sowing and plant population on performance of winter pigeonpea (Cajanus cajan). Indian Journal of Agricultural Sciences, New Delhi, v.61, n.6, p.425-426, 1991.

SINGH, L.; MAHESHWARI, S.K.; SHARMA, D. Effect of date of planting and plant population on growth, yield, yield components and protein content of pigeonpea [(Cajanus cajan (L.) Millsp.)]. Indian Journal of Agricultural Sciences, New Delhi, v.41, n.6, p.535-538, 1971.

WUTKE, E.B. Caracterização fenológica e avaliação agronômica de genótipos de guandu [(Cajanus cajan (L.) Millsp.)]. Piracicaba, 1987. 164p. Dissertação (Mestrado) ESALQ/USP.

WUTKE, E.B.; MIRANDA, M.A.C. de; AMBROSANO, E.J.; BRAGA, N.R.; BULISANI, E.A. Guandu-Cajanus cajan (L.) Millsp. In: FAHL, J.I.; CAMARGO, M.B.P. de; PIZZINATTO, M.A.; BETTI, J.A.; MELO, A.M.T. de; DE MARIA, I.C.; FURLANI, A.M.C. (Eds.). 6.ed. Instruções agrícolas para as principais culturas econômicas. Campinas, Instituto Agronômico, 1998. p.288-289. (Boletim Técnico, 200) 